\title{
Protein-energy wasting and asymmetric dimethylarginine in peritoneal dialysis patients
}

\author{
Sylwia Małgorzewicz' ${ }^{1}$ Zbigniew Heleniak² ${ }^{\bowtie}$, Monika Lichodziejewska-Niemierko², \\ Bolesław Rutkowski², Ewa Aleksandrowicz-Wrona' ${ }^{1}$ and Alicja Dębska-Ślizieńn ${ }^{2}$ \\ 1Department of Clinical Nutrition, ${ }^{2}$ Department of Nephrology, Transplantology and Internal Medicine, Medical University of Gdansk, Gdańsk, \\ Poland
}

Cardiovascular (CVS) morbidity and mortality in the peritoneal dialysis patients (PD) is 10-30-fold higher than in the general population. A relatively low level of adiponectin and a higher level of leptin are important predictors of vascular complications as well as CVS events in PD patients. The asymmetric dimethylarginine (ADMA), an endogenous inhibitor of nitric oxide synthase, is an important risk factor of CVS morbidity and mortality. It is very important to establish all CVS risk factors in the PD patients to prevent CVS morbidity and mortality in this population. The aim of the study was to determine the plasma concentration of ADMA and adipokines in relation to the protein-energy wasting (PEW) in PD patients. The study was performed in 30 PD patients and in the control group which consisted of 23 healthy volunteers. Plasma levels of hsC-reactive protein, TNF, IL-6, leptin, adiponectin, oxyLDL and ADMA were measured by ELISA method in both groups. The nutritional status was determined by measuring the albumin, body mass index (BMI), the percentage of body fat (\%F), lean body mass (LBM) and Subjective Global Assessment Score (SGA). The adequacy of dialysis was estimated by weekly Kt/V. In all PD patients, significantly higher levels of ADMA, leptin, oxyLDL, hsCRP and TNF in comparison to controls were observed. In contrast to well-nourished subjects, patients with PEW, in addition to increased hsCRP, showed significantly higher ADMA. PEW was associated with high levels of ADMA and hsCRP and this could probably be responsible for increased CVS risk in PD patients.

Key words: asymmetric dimethylarginine, protein energy wasting, peritoneal dialysis

Received: 19 June, 2018; revised: 21 October, 2018; accepted: 26 October, 2018; available on-line: 03 December, 2018

e-mail: zbigniew.heleniak@gumed.edu.pl

Abbreviations: ADMA, asymmetric dimethylarginine; BMI, body mass index; CKD, chronic kidney disease; CVS, cardiovascular; LBM, lean body mass; PD, peritoneal dialysis; PEW, protein-energy wasting; SGA, Subjective Global Assessment Score

\section{INTRODUCTION}

An important clinical issue in CKD (chronic kidney disease) patients is malnutrition or high risk of deterioration of nutritional status, lack of appetite and subclinical inflammation. In addition, the negative impact of the above on cardiovascular (CVS) risk of patients at various stages of CKD has also been found (ElMesallamy et al., 2008; Zoccali et al., 2005).
CVS morbidity and mortality in peritoneal dialysis (PD) patients is 10- to 30-fold higher than in the general population (Lim et al., 2015). The specific, non-traditional CVS risk factors for dialysis patients such as inflammation and hypoalbuminemia are the components of the protein-energy wasting (PEW) (Fouque et al., 2008; Zoccali et al., 2005). Subclinical inflammation, as well as metabolic disorders and abnormal nutritional status as a consequence, are highly unfavorable prognostic factors in PD patients. ADMA (asymmetric dimethylarginine), as a marker of accelerated atherosclerosis and endothelial dysfunction, is nowadays considered to be a good predictor of mortality in dialysis patients (Małgorzewicz et al., 2010; Ravani et al., 2005; Schepers et al., 2011; Scholze et al., 2007). Also, ADMA is postulated to be a link between CKD and CVS disease (Lim et al., 2015). Adipokines such as leptin and adiponectin are adipocyte-specific secretory proteins related to body mass and body fat content. Data from studies support the evidence that CVS risk in patients without CKD may be associated with hypoadiponectinemia and high levels of leptin (Tripepi et al., 2001). Data suggest that high plasma adiponectin levels may be related to a lower risk of coronary heart disease in the healthy population. In the PD population, relationships between nutritional status, inflammation and the levels of adipokines and other proatherosclerotic factors remain unclear.

The aim of the study was to determine the plasma concentration of ADMA and adipokines in the relation to the PEW in PD patients.

\section{PATIENTS AND METHODS}

Characteristics of the study groups. The group of 30 prevalent PD patients was recruited from The Peritoneal Dialysis Unit (Fresenius Medical Care in Gdańsk). 23 healthy volunteers were taken as a control group. The adequacy of the dialysis treatment was estimated by weekly Kt/V. The mean value of $\mathrm{Kt} / \mathrm{V}$ equaled $2.0 \pm 0.1$.

Inclusion and exclusion criteria. The inclusion criteria were as follows: age above 18 years, duration of peritoneal dialysis at least 3 months and stable parameters for at least 1 month, no signs of infection for a month before the study. The exclusion criteria were as follows: active malignancy, serious heart, lung or liver disease, lack of informed consent. PEW was determined by criteria which were introduced by the International Society of Renal Nutrition and Metabolism (ISRNM) in 2008 (7). In this study, the presence of PEW for every patient was 
Table 1. The anthropometrical and biochemical parameters and 7-SGA in the studied groups

\begin{tabular}{|c|c|c|c|c|c|}
\hline Parameters & $\begin{array}{l}\text { All PD } \\
n=30\end{array}$ & $\begin{array}{l}\text { PD without } \\
\text { PEW } \\
n=15\end{array}$ & $\begin{array}{l}\text { PD with } \\
\text { PEW } \\
n=15\end{array}$ & $\begin{array}{l}\text { Control } \\
n=23\end{array}$ & $\begin{array}{l}p \backslash P D \\
V S \\
\text { PEW }\end{array}$ \\
\hline Age [years] & $57.4 \pm 17.5$ & $54.4 \pm 15.6$ & $60.3 \pm 16.9$ & $63.3 \pm 7.8$ & 0.32 \\
\hline 7-SGA [points] & $5.3 \pm 1.2^{*}$ & $6.0 \pm 0.8$ & $4.5 \pm 0.9$ & - & 0.00 \\
\hline $\begin{array}{l}\text { Duration of PD treatment } \\
\text { [months] }\end{array}$ & $26.5 \pm 32.5$ & $16.1 \pm 18.2$ & $36.9 \pm 39.7$ & - & $0.07 ?$ \\
\hline $\mathrm{BMI}\left[\mathrm{kg} / \mathrm{m}^{2}\right]$ & $26.3 \pm 4.4$ & $27.3 \pm 5.0$ & $25.2 \pm 3.6$ & $26.9 \pm 1.7$ & 0.20 \\
\hline$\% \mathrm{~F}$ & $24.4 \pm 5.8$ & $26.0 \pm 6.2$ & $22.9 \pm 5.1$ & $26.2 \pm 4.9$ & 0.14 \\
\hline LBM $[\mathrm{kg}]$ & $53.0 \pm 12.5$ & $53.9 \pm 14.2$ & $52.1 \pm 11.1$ & $59.1 \pm 5.7$ & 0.70 \\
\hline Albumin $[\mathrm{g} / \mathrm{l}]$ & $3.9 \pm 5.3^{*}$ & $4.8 \pm 4.1$ & $3.4 \pm 1.8$ & $45.0 \pm 1.0$ & 0.00 \\
\hline Leptin $[\mu \mathrm{g} / \mathrm{l}]$ & $149.8 \pm 141.3^{*}$ & $197.1 \pm 144.7$ & $99.3 \pm 122.9$ & $14.2 \pm 8.5$ & 0.06 \\
\hline Adiponectin $[\mathrm{mg} / \mathrm{l}]$ & $25.0 \pm 12.0$ & $28.0 \pm 12.1$ & $28.0 \pm 11.5$ & $23.1 \pm 15.4$ & 0.19 \\
\hline ADMA $[\mu \mathrm{mol} / \mathrm{I}]$ & $2.9 \pm 2.3^{*}$ & $2.1 \pm 1.6$ & $3.8 \pm 2.6$ & $0.56 \pm 0.27$ & 0.03 \\
\hline IL-6 [pg/ml] & $3.3 \pm 5.7$ & $2.9 \pm 2.7$ & $3.7 \pm 5.9$ & $2.5 \pm 0.4$ & 0.70 \\
\hline $\mathrm{TNF}[\mathrm{pg} / \mathrm{ml}]$ & $5.3 \pm 9.3^{*}$ & $5.4 \pm 11.5$ & $5.1 \pm 6.5$ & $0.8 \pm 3.3$ & 0.94 \\
\hline $\mathrm{hsCRP}[\mathrm{mg} / \mathrm{l}]$ & $8.0 \pm 3.3^{*}$ & $6.7 \pm 3.9$ & $9.5 \pm 1.8$ & $0.7 \pm 0.5$ & 0.02 \\
\hline oxyLDL [ng/ml] & $543.9 \pm 442.8^{*}$ & $416.6 \pm 301$ & $680.8 \pm 460$ & $142.3 \pm 56.0$ & 0.11 \\
\hline
\end{tabular}

${ }^{*} p<0.05$ All PD vs control. 7-SGA - 7 points subjective global assessment, BMI - body mass index, \%F - percentage of body fat, LBM - lean body mass, ADMA - asymmetric dimethylarginine, IL-6 - interleukin 6, TNF - tumor necrosis factor, hs CRP - high sensitive C-reactive protein, oxyLDL oxidized low-density lipoprotein

assessed according to this definition, using the presence of at least three criteria as an indication of PEW:

serum albumin $<3.8 \mathrm{~g} / \mathrm{dl}$

BMI $<23$ or loss of $10 \%$ of normal body weight over 6 months

SGA $\leq 5$

Nutritional status. The nutritional status was estimated by the 7-point Subjective Global Assessment (7SGA) and serum concentration of albumin. Results of 7-SGA were scored as: 7-6 - good nutrition, 5-3 - mild malnutrition, 2-1 - severe malnutrition (6).

The body composition (body fat content and lean body mass) was measured by a near-infrared method (NIR) using Futrex 5000 A (Futrex Inc., USA).

BMI was calculated according to the equation: $\mathrm{BMI}=$ body weight/ height ${ }^{2}$

Biochemical assays. The samples of blood were taken from patients after overnight fasting. The serum concentration of albumin was measured by the bromocresol purple method.

The concentration of ADMA (asymmetric dimethylarginine), oxyLDL (oxidized low density lipoprotein), hsCRP (high sensitive C-reactive protein), TNF (tumor necrosis factor alpha), IL-6 (interleukin-6), leptin and adiponectin was assessed using ELISA method (Immunodiagnostik, Germany).

Statistical analysis. The data are expressed as means \pm S.D. (statistical deviation). Significant differences were defined as $p<0.05$. The correlation and significance were evaluated with nonparametric statistics ("Statistica version 12.0”; StatSoft, Polska, Krakow, 2017).

\section{RESULTS}

The anthropometrical and biochemical parameters and 7-SGA in the studied groups are presented in Table 1.

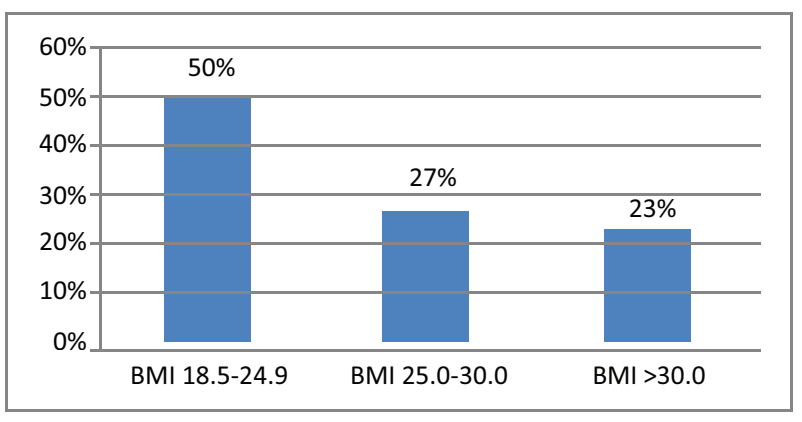

Figure 1. The BMI categories according to WHO in the PD patients.

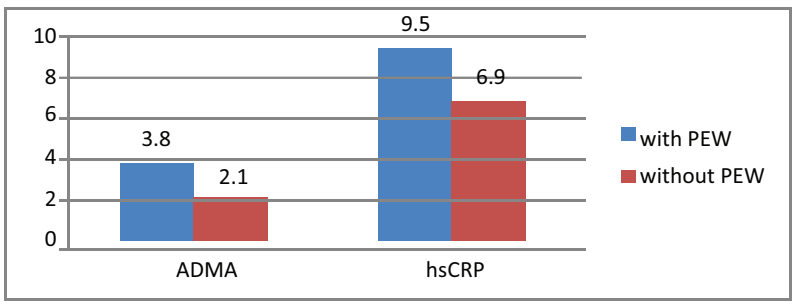

Figure 2. The hsCRP (mg/dl) and ADMA ( $\mu \mathrm{mol} / \mathrm{l})$ concentration in PD patients with and without protein-energy wasting $(p<0.05)$.

\section{Nutritional status}

We found that $50 \%$ of PD patients presented PEW. The BMI, body fat and LBM did not differ between PD patients and control. Figure 1 presents the percentage of PD patients in the respective BMI categories (according to WHO). 
In the PD group patients, the 7-SGA was positively correlated with s-albumin concentration ( $\mathrm{R}$ Spearman $=0.37$; $p<0.05$ ), BMI and $\% \mathrm{~F}$ (both - R Spear$\operatorname{man}=0.4 ; p<0.05)$. Also, leptin concentration was positively correlated with $\mathrm{BMI}$ and $\% \mathrm{~F}$ (R Spearman=0.4; $p<0.05)$.

\section{Biochemistry}

In the PD patients, significantly higher levels of ADMA, leptin, oxyLDL, hsCRP and TNF in comparison to the control group were observed. The adiponectin level did not differ between the studied groups ( $\mathrm{Ta}$ ble 1). s-Albumin negatively correlated with hsCRP (R Spearman $=-0.40 ; p<0.05)$.

In contrast to well-nourished subjects, patients with $\mathrm{PEW}$, in addition to significantly increased hsCRP $(p=0.02)$, showed significantly higher ADMA $(p=0.03)$. The association between PEW and hsCRP and ADMA is presented in Fig 2.

However, PEW patients were older than PD patients without PEW, with longer duration of dialysis treatment and with lower leptin level (see: Table 1).

\section{DISCUSSION}

Protein-energy wasting in dialysis patients is associated with higher risk of cardiovascular diseases and, in consequence, with poor prognosis. Both deterioration of the body composition and endothelial dysfunction are factors which play an important role in the progression of atherosclerosis. The assessment of nutritional status in our study was done comprehensively according to ISRNM recommendations (Fouque et al., 2008). Fifty percent of PD patients included in the study met the criteria for the diagnosis of PEW. Additionally, despite the normal or elevated BMI, the majority of PD patients $(80 \%)$ were at the risk of malnutrition or were mildly malnourished (based on 7-SGA). It is worth to underline that such a comprehensive assessment is necessary to obtain adequate results since the measurement of body mass and BMI itself is insufficient and not entirely reliable (Bogacka et al., 2018; Steiber et al., 2004). In our study, $50 \%$ of PD patients had low albumin level $(<3.8 \mathrm{~g} / \mathrm{dl})$. Higher serum albumin levels are associated with better prognosis, fewer complications, and longer survival time. In a large retrospective analysis, hypoalbuminemia $(<3.8 \mathrm{~g} / \mathrm{dl})$ was associated with longer hospitalization time and greater complication in dialysis patients (Balafa et al., 2011). In our study, similarly to other studies, chronic PD patients were characterized by elevated inflammatory markers (hsCRP, TNF), plasma levels of ADMA, oxyLDL and leptin (Guebre-Egziabher et al., 2004). In contrast to well-nourished PD subjects, patients with PEW, in addition to increased signs of inflammation, showed significantly higher ADMA level. Not significantly, but to some extent PEW was associated with a lower leptin level, and longer duration of PD treatment (Table 1). As mentioned above, subclinical inflammation, which occurs in a significant proportion of PD patients contributes to many metabolic disorders (eg. insulin resistance), anorexia and, consequently, to abnormal nutritional status (Young). Indeed, the investigated inflammatory marker - hsCRP, indicated the presence of chronic inflammation in most of the subjects, although no clinical evidence of infection was observed. Moreover, what was extremely important was the significant negative correlation between hsCRP and biochemical parameters of the nutritional status (s-albumin). The above observation also seemed to be highly relevant clinically (Alves et al., 2018; Balafa et al., 2011).

The influence of malnutrition and inflammation on serum level of ADMA was demonstrated by Zoccali in hemodialysis patients (Zoccali et al., 2001). In our study, we observed that the level of ADMA was significantly higher in PD patients as compared to the healthy subjects. This is consistent with the data in the literature indicating that $\mathrm{CKD}$ contributes to the increased levels of ADMA in this group of patients (Zhao et al., 2014).

It is also worth to mention that among all PD patients as well as in PD patients with PEW coexisted both high ADMA and elevated markers of inflammation (CRP, IL6 , TNF). The relationship between the concentration of ADMA and the indicator of inflammation status (CRP) was confirmed in patients with end-stage renal disease (ESRD) (Ravani et al., 2005).

It was proven that both ADMA and CRP are predictors of CVS events in CKD patients (Zoccali et al., 2001; Aucella et al., 2009). Moreover, Tripepi et al. demonstrated that the simultaneous increase in ADMA and CRP (or IL-6) causes an increased risk of death and CVS events in patients with ESRD followed up for 13 years (Tripepi et al., 2011). These data are consistent with previous reports, in which in the group of patients with ESRD, the effect of ADMA and CRP on the progression of atherosclerosis was presented (Schepers et al., 2011).

However, in contrast to hemodialysis patients, in our PD group, ADMA levels were not related to BMI and albumin. Also, there was no significant correlation between ADMA and CRP or IL-6.

In PD patients, local inflammation within the peritoneal cavity may be the main cause of the high CRP level Additionally, our limited sample size, study protocol and relatively short dialysis vintage (median was 11 months) may be the cause of the lack of a clear association between ADMA and inflammatory markers.

Previously, it was demonstrated that adiponectin has potential anti-inflammatory and anti-atherogenic properties due to its adhesion molecules acting as a protective factor against atherogenesis (Xu et al., 2018). Another adipokine, leptin, regulates the amount of body fat, food intake and energy homeostasis; leptin levels show a positive correlation with body fat mass (Silha et al., 2003). In a prospective long-term study, Scholze and others (Scholze et al., 2007) showed that reduced serum leptin concentration is an independent risk factor for mortality in patients on hemodialysis therapy. However, according to the other authors, the elevated leptin level, associated with high body fat content and low lean body mass in PD patients, may be a risk factor of malnutrition (Lam et al., 2007).

Serum leptin levels were previously reported to be elevated in patients with chronic renal failure and to correlate with CRP levels suggesting that inflammation may be an important factor in the development of hyperleptinemia in CKD (Mak et al., 2006).

Our study showed increased leptin levels in PD patients in comparison to controls and some association between lower leptin level and PEW (not significant). Similarly to the previous studies, leptin level correlated positively with body mass and body fat (Małgorzewicz et al., 2010; Delgado et al., 2017).

To summarize, we would like to underline that all studied non-traditional CVS risk factors were elevated in PD patients. PEW correlated with high levels of ADMA and hsCRP and it can at least partially be responsible for increased CVS risk in PD patients. Therefore the fur- 
ther, long-term observation of nutritional status and adipokines and ADMA concentration is needed.

\section{REFERENCES}

Aucella F, Maas R, Vigilante M, Tripepi G, Schwedhelm E, Margaglione M, Gesualdo L, Boeger R, Zoccali C (2009) Methylarginines and mortality in patients with end stage renal disease: a prospective cohort study. Atherosclerosis 207: 541-545

Alves FC, Sun J, Qureshi AR, Dai L, Snaedal S, Bárány P, Heimbürger O, Lindholm B, Stenvinkel P (2018) The higher mortality associated with low serum albumin is dependent on systemic inflammation in end-stage kidney disease. PLoS One 3: e0190410. https://doi. org/10.1371/journal.pone.0190410

Balafa O, Halbesma N, Struijk DG, Dekker FW, Krediet RT (2011) Peritoneal albumin and protein losses do not predict outcome in peritoneal dialysis patients. Clin J Am Soc Nephrol 6: 561-566. doi: 10.2215/CJN.05540610

Bogacka A, Sobczak-Czynsz A, Kucharska E, Madaj M, Stucka K (2018) Analysis of nutrition and nutritional status of haemodialysis patients. Rocz Panstw Zakel Hig 69: 165-174 (in Polish?)

Delgado C, Chertow GM, Kaysen GA, Dalrymple LS, Kornak J, Grimes B, Johansen KL (2017) Associations of body mass index and body fat with markers of inflammation and nutrition among patients receiving hemodialysis. Am J Kidney Dis 70: 817-825. doi: 10.1053/j.ajkd.2017.06.028

El-Mesallamy HO, Abdel Hamid SG, Gad MZ (2008) Oxidative stress and asymmetric dimethylarginine are associated with cardiovascular complications in hemodialysis patients: improvements by L-arginine intake. Kidney Blood Press Res 31: 189-195. doi: 10.1159/000135655

Fouque D, Kalantar-Zadeh K, Kopple J, Cano N, Chauveau P, Cuppari L, Franch H, Guarnieri G, Ikizler TA, Kaysen G, Lindholm B, Massy Z, Mitch W, Pineda E, Stenvinkel P, Treviño-Becerra A, Wanner C (2008) A proposed nomenclature and diagnostic criteria for protein-energy wasting in acute and chronic kidney disease. Kidney Int 73: 391-398. doi: 10.1038/sj.ki.5002585

Guebre-Egziabher F, Drai J, Fouque D (2004) Adiponectin and chronic kidney disease. J Ren Nutr 17: 9-12. https://doi.org/10.1053/j. jrn.2006.10.003

Lam MF, Leung JC, Lo WK, Tam S, Chong MC, Lui SL, Tse KC, Chan TM, Lai KN (2007) Hyperleptinaemia and chronic inflammation after peritonitis predicts poor nutritional status and mortality in patients on peritoneal dialysis. Nephrol Dial Transplant 22: 14451450. doi: $10.1093 / \mathrm{ndt} / \mathrm{gfl} 788$

Lim CT, Yap XH, Chung KJ, Khalid MA, Yayha N, Latiff LA, Goh BL (2015) Predictor of cardiovascular risks in end stage renal failure patients on maintenance dialysis. Pak J Med Sci 31: 1300-1305. doi: $10.12669 /$ pjms.316.8039

Mak RH, Cheung W, Cone RD, Marks DL (2006) Leptin and inflammation-associated cachexia in chronic kidney disease. Kidney Int 69: 794-797. doi: 10.1038/sj.ki.5000182
Małgorzewicz S, Lichodziejewska-Niemierko M, Aleksandrowicz-Wrona E, Świetlik D, Rutkowski B, Łysiak-Szydłowska W (2010) Adipokines, endothelial dysfunction and nutritional status in peritoneal dialysis patients. Scand J Urol Nephrol 44: 44-45

Ravani P, Tripepi G, Malberti F, Testa S, Mallamaci F, Zoccali C (2005) Asymmetrical dimethylarginine predicts progression to dialysis and death in patients with chronic kidney disease: a competing risks modeling approach. I Am Soc Nephrol 16: 2449-2455

Schepers E, Barreto DV, Liabeuf S, Glorieux G, Eloot S, Barreto FC, Massy Z, Vanholder R, European Uremic Toxin Work Group (EUTox) (2011) Symmetric dimethylarginine as a proinflammatory agent in chronic kidney disease. Clin I Am Soc Nephrol 6: 2374-2383

Scholze A, Tepel M (2007) Role of leptin in reverse epidemiology in chronic kidney disease. Semin Dial 20: 534-538

Silha JV, Krsek M, Skrha JV, Sucharda P, Nyomba BL, Murphy LJ (2003) Plasma resistin, adiponectin and leptin levels in lean and obese subjects: correlations with insulin resistance. Eur J Endocrinol 149: 331-335. doi: 10.1111/j.1464-5491.2004.01178.x

Steiber AL, Kalantar-Zadeh K, Secker D, McCarthy M, Sehgal A, McCann L (2004) Subjective global assessment in chronic kidney disease. A Review. J Ren Nutr 14: 191-200. doi: https://doi. org/10.1053/j.jrn.2004.08.004

Tripepi G, Raso FM, Sijbrands E, Seck MS, Maas R, Boger R, Witteman J, Rapisarda F, Malatino L, Mallamaci F, Zoccali C (2011) Inflammation and asymmetric dimethylarginine for predicting death and cardiovascular events in ESRD patients. Clin J Am Soc Nephrol 6: $1714-1721$

Wiecek A, Kokot F, Chudek J, Adamczak M (2002) The adipose tissue - a novel endocrine organ of interest to the nephrologist. Nephrol Dial Transplant 17: 191-195

Xu X, Tian X, Chen Y, Yang ZK, Qu Z, Dong J (2018) Associations of adiponectin, leptin levels, and the change of body composition in patients on peritoneal dialysis: a prospective cohort study. Perit Dial Int 38: 278-285. doi: 10.3747/pdi.2017.00177

Young V, Balaam S, Orazio L, Bates A, Badve SV, Johnson DW, Campbell KL (2016) Appetite predicts inyake and nutritional status in patients recewing peritoneal dialysis. J Ren Care 42: 123-131. doi: 10.1111/jorc. 12156

Zhao JR, Zhang DY, Sun D (2014) Correlation research on ADMA plasma levels and left ventricular function of peritoneal dialysis patients. Int J Clin Exp Med 15: 4455-4460

Zoccali C, Bode-Boger S, Mallamaci F, Benedetto F, Tripepi G, Malatino L, Cataliotti A, Bellanuova I, Fermo I, Frölich J, Böger R (2001) Plasma concentration of asymmetrical dimethylarginine and mortality in patients with end-stage renal disease: a prospective study. Lancet 358: 2113-2117. https://doi.org/10.1016/S0140-6736(01)07217-8

Zoccali C, Enia G, Tripepi G, Panuccio V, Mallamaci F (2005) Clinical epidemiology of major non-traditional risk factors in peritoneal dialysis patients. Perit Dial Int 25 (Suppl 3): 84-87 